Article

\title{
Use of Phosphate Solubilizing Bacteria to Leach Rare Earth Elements from Monazite-Bearing Ore
}

\author{
Doyun Shin ${ }^{1,2, *}$, Jiwoong Kim ${ }^{1}$, Byung-su Kim ${ }^{1,2}$, Jinki Jeong ${ }^{1,2}$ and Jae-chun Lee ${ }^{1,2}$ \\ 1 Mineral Resources Resource Division, Korea Institute of Geoscience and Mineral Resources \\ (KIGAM), Gwahangno 124, Yuseong-gu, Daejeon 305-350, Korea; \\ E-Mails: jwk@kigam.re.kr (J.K.); bskim@kigam.re.kr (B.K.); jinkiz@kigam.re.kr (J.J.); \\ jclee@kigam.re.kr (J.L.) \\ 2 Department of Resource Recycling Engineering, Korea University of Science and Technology, \\ Gajeongno 217, Yuseong-gu, Daejeon 305-350, Korea
}

* Author to whom correspondence should be addressed; E-Mail: doyun12@kigam.re.kr; Tel.: +82-42-868-3616.

Academic Editor: Anna H. Kaksonen

Received: 8 January 2015 / Accepted: 27 March 2015 / Published: 2 April 2015

\begin{abstract}
In the present study, the feasibility to use phosphate solubilizing bacteria (PSB) to develop a biological leaching process of rare earth elements (REE) from monazite-bearing ore was determined. To predict the REE leaching capacity of bacteria, the phosphate solubilizing abilities of 10 species of PSB were determined by halo zone formation on Reyes minimal agar media supplemented with bromo cresol green together with a phosphate solubilization test in Reyes minimal liquid media as the screening studies. Calcium phosphate was used as a model mineral phosphate. Among the test PSB strains, Pseudomonas fluorescens, P. putida, P. rhizosphaerae, Mesorhizobium ciceri, Bacillus megaterium, and Acetobacter aceti formed halo zones, with the zone of $A$. aceti being the widest. In the phosphate solubilization test in liquid media, Azospirillum lipoferum, P. rhizosphaerae, B. megaterium, and $A$. aceti caused the leaching of $6.4 \%, 6.9 \%, 7.5 \%$, and $32.5 \%$ of calcium, respectively. When PSB were used to leach REE from monazite-bearing ore, $\sim 5.7 \mathrm{mg} / \mathrm{L}$ of cerium $(0.13 \%$ of leaching efficiency) and $\sim 2.8 \mathrm{mg} / \mathrm{L}$ of lanthanum (0.11\%) were leached by $A$. aceti, and Azospirillum brasilense, A. lipoferum, $P$. rhizosphaerae and $M$. ciceri leached $0.5-1 \mathrm{mg} / \mathrm{L}$ of both cerium and lanthanum $(0.005 \%-0.01 \%)$, as measured by concentrations in the leaching liquor. These results indicate that determination of halo zone formation was found as a useful method to select
\end{abstract}


high-capacity bacteria in REE leaching. However, as the leaching efficiency determined in our experiments was low, even in the presence of $A$. aceti, further studies are now underway to enhance leaching efficiency by selecting other microorganisms based on halo zone formation.

Keywords: bioleaching; monazite; phosphate solubilizing bacteria; rare earth element

\section{Introduction}

Rare earth elements (REE) have been increasingly used in the fields of optics, permanent magnetism, electronics, superconductor technology, hydrogen storage, medicine, nuclear technology, secondary battery technology, and catalysis [1-3]. The minerals monazite (a phosphate mineral) and bastnasite (a fluorocarbonate mineral) are the main sources of REE in nature. Generally, monazite contains $\sim 70 \%$ rare earth metal oxide, with the rare earth fraction comprising $20 \%-30 \% \mathrm{Ce}_{2} \mathrm{O}_{3}$, $10 \%-40 \% \mathrm{La}_{2} \mathrm{O}_{3}$, and substantial amounts of neodymium, praseodymium, and samarium. The thorium content is in the range of $4 \%-12 \%[2,3]$.

Caustic soda decomposition and concentrated sulfuric acid digestion have been widely used to decompose monazite for many decades $[2,4]$. Due to its high chemical and thermal stability, monazite is very difficult to decompose; therefore, it is essential to eliminate the phosphate present in the ore by chemically attacking the mineral with sulfuric acid or sodium hydroxide at high temperature, so as to enhance the capacity to dissolve the REE. The sulfuric acid process results in a loss of phosphate as $\mathrm{H}_{3} \mathrm{PO}_{4}$, corrosion of the processing facilities, toxic gas and wastewater generation, as well as yielding impure products; the process is therefore no longer in commercial use. Caustic soda decomposition has some advantages in terms of the recovery of unreacted alkali and phosphorous, low energy consumption, and simplicity; however, the process also has limitations, such as the need for high-grade ore sources $[5,6]$.

Biohydrometallurgical technology is an attractive alternative emerging green technology for the recovery of metals due to its environmental friendly, simple, and economic processing. However, very few works have been published on the biological recovery of rare earth metals, in particular, from monazite. Recently thorium, uranium, and REE extraction by microorganisms from monazite concentrate was reported [7,8]. The authors used Aspergillus ficuum, organic acid producing fungi, and Pseudomonas aeruginosa, organic acid/siderophore producing bacteria. They found that those microorganisms produced citric, oxalic, or 2-ketogluconic acid and dissolved 55\% and 47\% of REE from monazite by A. ficuum and P. aerunoginosa, respectively. Another study on REE leaching from phosphate minerals apatite and monazite by organic acids such as citric, oxalic, phthalic, and salicylic was also published, even though chemical organic acids were used in this study, which were not biologically produced [9]. Organic acid producing microorganisms secrete organic acids such as malic, gluconic, or oxalic acids $[10,11]$, and the mechanism of metal dissolution by the microorganisms is both of acidolysis (protons dissociated from the organic acids) and complexolysis (metal-complexing anions from the acids) [12]. 
In a soil improvement process, phosphate solubilizing bacteria (PSB) have been widely used because they affect the release of phosphorous (P) from inorganic and organic $\mathrm{P}$ pools through solubilization and mineralization [13-15] by organic acid production. In the present study, we investigated the feasibility to use PSB in REE leaching from monazite-bearing ore as an exploratory study. Screening studies were performed by determining halo zone formation on agar media and phosphate solubilization in liquid media to predict REE leaching capacity of bacteria. The REE leaching abilities of the PSB from monazite-bearing ore were determined and compared with the screening data.

\section{Experimental Section}

\subsection{Bacterial Strains and Culture Conditions}

Ten PSB strains, Pseudomonas rhizosphaerae DSM 16299 $[16]$, P. putida DSM 291 ${ }^{\mathrm{T}}$, P. fluorescens DSM 50090 [17], Bacillus megaterium DSM 32 ${ }^{\mathrm{T}}$ [18], Paenibacillus polymyxa DSM $36^{\mathrm{T}}$ [14], Ensifer meliloti DSM 30135 [19], Azospirillum brasilense DSM 1690 ${ }^{\mathrm{T}}$, A. lipoferum DSM 1842 [17], Mesorhizobium ciceri, and Acetobacter aceti DSM 2002 were selected, purchased from Deutsche Sammlung von Mikroorganismen und Zellkulturen (DSMZ; Braunschweig, Germany), and maintained on nutrient agar (NA) at $30{ }^{\circ} \mathrm{C}$. For the organic acid production test, the phosphate solubilization test, and the RE leaching study, Reyes minimal medium (in $1 \mathrm{~L}: 0.4 \mathrm{~g} \mathrm{NH}_{4} \mathrm{Cl} ; 0.78 \mathrm{~g} \mathrm{KNO}_{3}$; $0.1 \mathrm{~g} \mathrm{NaCl} ; 0.5 \mathrm{~g} \mathrm{MgSO}_{4} \cdot 7 \mathrm{H}_{2} \mathrm{O} ; 0.1 \mathrm{~g} \mathrm{CaCl}_{2} \cdot 2 \mathrm{H}_{2} \mathrm{O} ; 0.5 \mathrm{mg} \mathrm{FeSO} \cdot 7 \mathrm{H}_{2} \mathrm{O} ; 1.56 \mathrm{mg} \mathrm{MnSO}_{4} \cdot \mathrm{H}_{2} \mathrm{O}$; $1.40 \mathrm{mg} \mathrm{ZnSO} \cdot 7 \mathrm{H}_{2} \mathrm{O}$ ) [20] was used. Glucose or sucrose was added at $30 \mathrm{~g} / \mathrm{L}$ as a carbon source and $\mathrm{Ca}_{3}\left(\mathrm{PO}_{4}\right)_{2}(5.39 \mathrm{~g} / \mathrm{L})$, alkaline metal phosphate, was used as a sole phosphate source. The viable bacterial cell number was measured by the plate counting method on NA at $30{ }^{\circ} \mathrm{C}$.

\subsection{Comparison of Halo Zone Formation, Organic Acid Production, and Phosphate Solubilization by} Phosphate Solubilizing Bacteria

Halo zone formation by test PSB strains were tested using Reyes minimal medium supplemented with $1.5 \%$ agar, $5.39 \mathrm{~g} / \mathrm{L} \mathrm{Ca} 3\left(\mathrm{PO}_{4}\right)_{2}$ as a mineral phosphate, $30 \mathrm{~g} / \mathrm{L}$ glucose or sucrose as a carbon source, and bromocresol green (BCG) as a $\mathrm{pH}$ indicator. The $\mathrm{pH}$ of the medium was adjusted to 6.5 using $1 \mathrm{~N} \mathrm{KOH}$. A $0.5 \%$ BCG solution was prepared in $70 \%$ ethanol as a stock solution and a $0.5 \mathrm{~mL}$ aliquot of the solution was added to $100 \mathrm{~mL}$ of Reyes minimal agar medium before autoclaving. Twenty microliters of PSB pregrown in nutrient broth was dot inoculated onto the surface of the agar plate prepared as above, incubated at $30{ }^{\circ} \mathrm{C}$ for $48 \mathrm{~h}$. The total halo diameter and colony diameter were measured; halo size was calculated by subtracting the colony diameter from the total halo diameter.

A quantitative estimate of organic acid production by the PSB was performed using a 50-mL conical tube containing $30 \mathrm{~mL}$ of Reyes minimal medium supplemented with $0.45 \mathrm{~g} / \mathrm{L} \mathrm{KH}_{2} \mathrm{PO}_{4}$ and $30 \mathrm{~g} / \mathrm{L}$ glucose, and inoculated with the bacterial strain $\left(3 \mathrm{~mL}\right.$ inoculum with approximately $10^{8} \mathrm{CFU}$ (colony forming unit) $/ \mathrm{mL}$ ). To measure the organic acid producing ability of the test PSB without any interference, $\mathrm{KH}_{2} \mathrm{PO}_{4}$ was used as an easily edible form of phosphate source because the availability of a phosphate source may affect organic acid production. An autoclaved uninoculated medium served as a control. The vials were incubated for 11 days in a shaking incubator at $30^{\circ} \mathrm{C}$ and $180 \mathrm{rpm}$. At 1-day 
intervals, individual cultures were centrifuged at $5000 \mathrm{~g}$ for $30 \mathrm{~min}$, and the supernatant was filtered with a $0.22-\mu \mathrm{m}$ pore syringe filter. Concentrations of citric acid $\left(\mathrm{C}_{6} \mathrm{H}_{8} \mathrm{O}_{7}\right)$, malic acid $\left(\mathrm{C}_{4} \mathrm{H}_{6} \mathrm{O}_{5}\right)$, tartaric acid $\left(\mathrm{C}_{4} \mathrm{H}_{6} \mathrm{O}_{6}\right)$, and acetic acid $\left(\mathrm{C}_{2} \mathrm{H}_{4} \mathrm{O}_{2}\right)$ in the culture were determined by high-performance liquid chromatography (HPLC) (2690 Separation Module, Waters Alliance System, Milford, MA, USA) with $20 \mathrm{mM} \mathrm{NaH} 2 \mathrm{PO}_{4}(\mathrm{pH} 2.7$, adjusted with 20\% phosphoric acid), using an Atlantis T3 column $(5 \mu \mathrm{m} ; 4.6 \mathrm{~mm} \times 250 \mathrm{~mm})$, and quantified using a Waters 996 Photo-diode Array Detector at $210 \mathrm{~nm}$.

Phosphate solubilization_by the test PSB in liquid media was determined in Reyes minimal medium supplemented with $\mathrm{Ca}_{3}\left(\mathrm{PO}_{4}\right)_{2}(5.39 \mathrm{~g} / \mathrm{L})$ and glucose $(30 \mathrm{~g} / \mathrm{L})$. The cultivation procedure was as described above, except for the incubation time (i.e., 5 days). Total calcium concentrations were determined by inductively coupled plasma atomic emission spectrometry (ICP-AES) (Optima 5300DV, Jobin Yvon JY 38, ICAP 6500 DVO; Perkin Elmer, Shelton, CT, USA); phosphate concentrations were determined by ion chromatography (IC) (ICS-3000, Dionex, Sunnyvale, CA, USA). Values reported are the average of three replicates.

\subsection{Ore Characterization}

The elemental composition of the raw monazite-bearing ore used in this study is shown in Table 1, which was measured by alkali fusion with $\mathrm{Na}_{2} \mathrm{CO}_{3}$ for silica, permanganametric titration for calcium, and ICP after multi-acid digestion for the other elements [21]. The mineralogical and morphological data of the ore were obtained by X-Ray Diffraction (XRD; Model RTP 300 RC, Rigaku Co., Tokyo, Japan) and a scanning electron microscope (SEM, JEOL 6400; JEOL Ltd., Tokyo, Japan) equipped with energy dispersive spectroscopy (EDS). The semi-quantification spot analysis SEM-EDS was performed using Thin Film Standardless Standard Quantitative Analysis (Oxide).

Table 1. Elemental analysis of monazite-bearing ore used in this study.

\begin{tabular}{cccccccccccccc}
\hline Element & $\mathrm{Ce}$ & $\mathrm{La}$ & $\mathrm{Nd}$ & $\mathrm{Pr}$ & $\mathrm{SiO}_{2}$ & $\mathrm{Al}_{2} \mathrm{O}_{3}$ & $\mathrm{Fe}_{2} \mathrm{O}_{3}$ & $\mathrm{CaO}$ & $\mathrm{MgO}$ & $\mathrm{K}_{2} \mathrm{O}$ & $\mathrm{Sr}$ & $\mathrm{TiO}_{2}$ & $\mathrm{P}_{2} \mathrm{O}_{5}$ \\
\hline Content (wt\%) & 3.50 & 2.09 & 0.75 & 0.21 & 12.77 & 0.73 & 39.80 & 7.52 & 6.26 & $<0.001$ & 0.47 & 0.02 & 5.33 \\
\hline
\end{tabular}

\subsection{Monazite-Bearing Ore Leaching by Phosphate Solubilizing Bacteria}

The monazite-bearing ore was ground and then sieved below $150 \mu \mathrm{m}$ size. A solution of $30 \mathrm{~mL}$ Reyes minimal medium (prepared as above) containing $30 \mathrm{~g} / \mathrm{L}$ of glucose was added to 50 -mL conical tubes containing $5 \mathrm{~g}$ of the autoclaved ore. Leaching was run for 9 days in a shaking incubator at $30{ }^{\circ} \mathrm{C}$ and $180 \mathrm{rpm}$. On each of the 9 days, samples were taken and prepared independently for further analysis. Total cerium and lanthanum concentrations in the residue and the liquor were determined by ICP and the mineralogical change of the residue was analyzed by SEM-EDS and XRD.

\section{Results and Discussion}

\subsection{Comparison of Phosphate Solubilization by Phosphate Solubilizing Bacteria}

Ten PSB strains (as stated above) were selected based on the literature reviews of their potential for phosphate solubilization. The halo zone formation was determined as a screening study to investigate 
the phosphate solubilizing ability of the PSB. Due to the production of organic acids in the surrounding medium, the halo zone on the agar plate was formed by converting insoluble phosphate into soluble phosphate [22]. The converting efficiencies vary for different forms of phosphate (i.e., $\mathrm{Ca}_{3}\left(\mathrm{PO}_{4}\right)_{2}$, $\mathrm{AlPO}_{4}$, and $\mathrm{FePO}_{4}$ ); among them, calcium phosphate was most aggressively attacked by PSB. Higher phosphate solubilization from calcium phosphate than from aluminum and iron phosphate minerals has been reported, based on the solubility equilibrium and acidity constants of these compounds [23], thus $\mathrm{Ca}_{3}\left(\mathrm{PO}_{4}\right)_{2}$ was used in this study as a mineral phosphate. Bromocresol green (BCG) was also added in Reyes minimal medium supplemented with glucose and sucrose to improve the clarity and visibility of the yellow-colored halo zone [11]. The test PSB formed different sizes of distinct halo zones on the media depending on the bacterial strain and carbon source (Table 2). The widest halo zone was observed in the presence of $A$. aceti (diameter, $41.0 \mathrm{~mm}$ ) on media supplemented with glucose; $P$. rhizosphaerae, P. fluorescens, B. megaterium, and $M$. ciceri also formed halo zones, while P. polymyxa, E. meliloti, A. brasilense, and A. lipoferum did not form halo zones on the media supplemented with either glucose or sucrose. Wider halo zones were observed in most samples when glucose was present rather than when sucrose was present; therefore, glucose was used as a carbon source throughout this study. Also, the use of modified Reyes agar medium supplemented with BCG and glucose was the most effective condition to determine halo zone formation.

Table 2. Comparison of tricalcium phosphate solubilization by phosphate solubilizing bacteria (PSB) in Reyes minimal agar medium supplemented with bromocresol green $(\mathrm{BCG})$ and $30 \mathrm{~g} / \mathrm{L}$ of glucose or sucrose, associated with microbial growth for $24 \mathrm{~h}$.

\begin{tabular}{ccc}
\hline Bacterial Species & \multicolumn{2}{c}{ Halo Size $(\mathbf{m m}) *$} \\
\cline { 2 - 3 } Glucose & Sucrose \\
\hline P. rhizosphaerae DSM $16299^{\mathrm{T}}$ & 13.5 & 13.4 \\
P. putida DSM $291^{\mathrm{T}}$ & $-* *$ & 7.2 \\
P. fluorescens DSM $50090^{\mathrm{T}}$ & 5.6 & 7.8 \\
B. megaterium DSM $32^{\mathrm{T}}$ & 4.7 & 12.1 \\
P. polymyxa DSM $36^{\mathrm{T}}$ & - & - \\
E. meliloti DSM $30135^{\mathrm{T}}$ & - & - \\
A. brasilense DSM $1690^{\mathrm{T}}$ & - & - \\
A. lipoferum DSM 1842 & - & - \\
M. ciceri & 5.1 & 4.4 \\
A. aceti $\mathrm{DSM} 2002$ & 41.0 & 12.58 \\
\hline
\end{tabular}

* The total halo diameter and colony diameter were measured; halo size was calculated by subtracting the colony diameter from the total halo diameter. ** “-” represents no halo zone formation.

Concentrations of solubilized phosphate and calcium ion in the Reyes minimal medium supplemented with glucose and $\mathrm{Ca}_{3}\left(\mathrm{PO}_{4}\right)_{2}$ were analyzed for a period of five days, to compare the phosphate solubilizing ability of PSB. The viable PSB cell numbers were maintained at approximately $10^{7} \mathrm{CFU} / \mathrm{mL}$ medium during the experimental periods. The leaching efficiency was calculated by subtracting the mass of calcium and phosphate in the uninoculated control from the mass in the leaching liquor and dividing the leached mass by the total mass. The leaching efficiencies were shown to be highest generally within two to three days of incubation; thereafter, concentrations of leached 
phosphate and calcium decreased, possibly due to uptake by the PSB or absorption onto bacterial surfaces. The highest leaching efficiencies after three days of leaching were presented by A. lipoferum, P. rhizosphaerae, and B. megaterium $(6.4 \%, 6.9 \%$, and $7.5 \%$, respectively, for calcium; and $3.7 \%$, $6.8 \%$, and $5.7 \%$, respectively, for phosphate (Figure 1); leaching efficiencies by A. brasilense and E. meliloti were less than $2 \%$ for calcium; as expected, A. aceti showed the highest leaching efficiency of calcium $(\sim 32.5 \%)$.

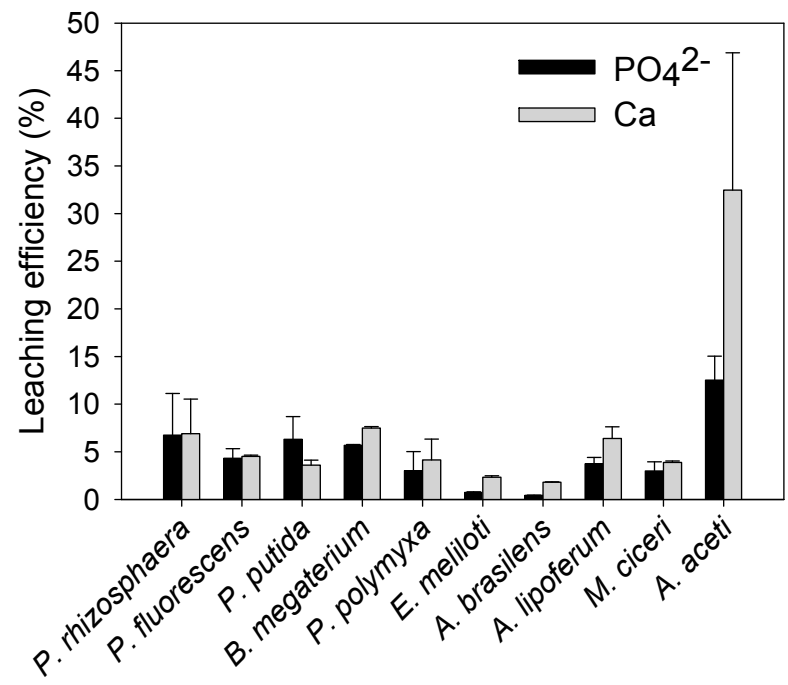

Bacterial strain

Figure 1. Phosphate and calcium solubilization from $\mathrm{Ca}_{3}\left(\mathrm{PO}_{4}\right)_{2}$ in Reyes basal liquid medium, associated with microbial growth after 3 days.

Inorganic phosphate solubilization by PSB depends on organic acid secretion from PSB [14]. Citric, malic, tartaric, and acetic acids were measured by HPLC in $30-\mathrm{mL}$ of the PSB cultures containing $\mathrm{KH}_{2} \mathrm{PO}_{4}$ and glucose (Figure 2). The test PSB strains showed organic acid production below $\sim 0.2 \mathrm{mmol}$, except for $A$. aceti. The maximum malic acid produced by A. brasilense, A. lipoferum, M. ciceri, and $P$. rhizosphaerae occurred at $0.07 \mathrm{mmol}$ at six days, $0.09 \mathrm{mmol}$ at nine days, $0.06 \mathrm{mmol}$ at eight days, and $0.18 \mathrm{mmol}$ at six days, respectively (maximum production). Acetic acid was produced by $A$. aceti, with concentrations reaching a maximum of $15.8 \mathrm{mM}(0.48 \mathrm{mmol})$ at four days of incubation. Hwangbo et al. [24] reported that Enterobacter intermedium produced gluconic acid from glucose and subsequently converted it to 2-ketogluconic acid, which has a strong ionic strength and therefore easily solubilizes rock phosphate into soluble forms. The same situation was reported when Acetobacter was used to produce gluconic acid [25]. Because of the conversion of gluconic acid as stated above, gluconic acid might not be detected in the microbial cultures in this study. After six days, the amount of malic and acetic acid decreased. The $\mathrm{pH}$ of the media during incubation showed similar trends with organic acid production (Figure 3 ) because the $\mathrm{pH}$ decrease is due to the excreted metabolites, which included proton from organic acids, amino acids, and other metabolites. The $\mathrm{pH}$ in the medium of $A$. aceti decreased to about $\mathrm{pH} 3$ (corresponding $\mathrm{pH}$ to $\sim 15 \mathrm{mM}$ of acetic acid, which was the acid produced) until eight days of incubation, and subsequently increased. The acidities of the media for A. brasilense, A. lipoferum, and $P$. rhizosphaerae also showed similar trends with acetic acid, with $\mathrm{pH}$ decreasing (i.e., 3-4) until six to seven days of incubation and increasing thereafter. 

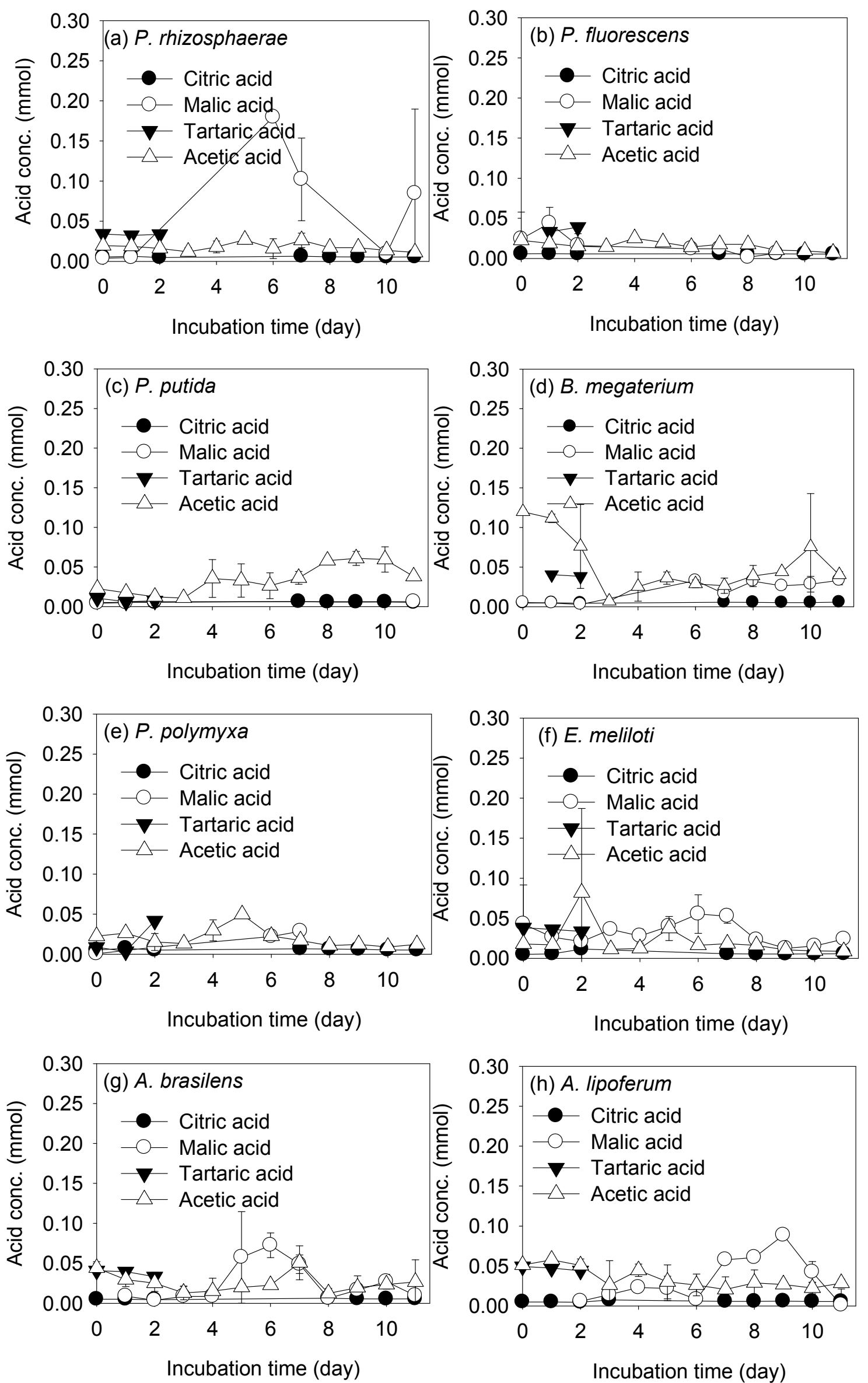

Figure 2. Cont. 

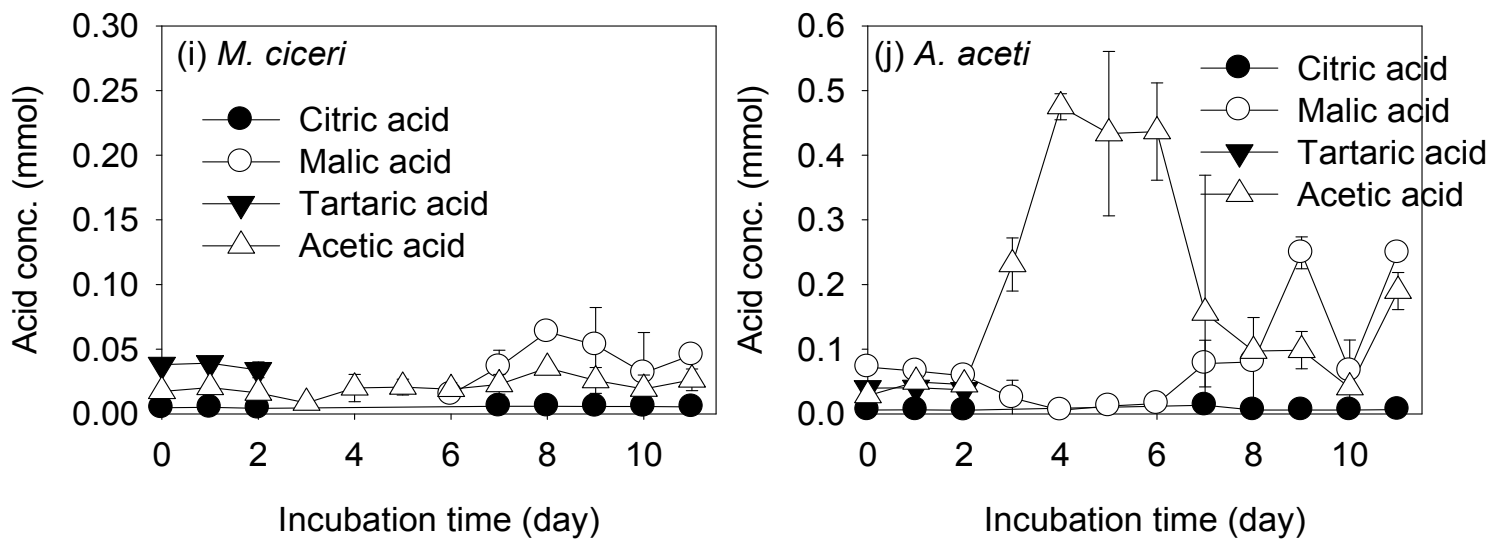

Figure 2. Organic acid production of (a) P. rhizosphaerae DSM $16299^{\mathrm{T}}$, (b) P. fluorescens DSM 50090 ${ }^{\mathrm{T}}$, (c) P. putida DSM 291 ${ }^{\mathrm{T}}$, (d) B. megaterium DSM 32 ${ }^{\mathrm{T}}$, (e) P. polymyxa DSM 36 ${ }^{\mathrm{T}}$, (f) E. meliloti DSM 30135, (g) A. brasilense DSM 1690 ${ }^{\mathrm{T}}$, (h) A. lipoferum DSM 1842, (i) M. ciceri, and (j) A. aceti in Reyes basal liquid medium supplemented with $\mathrm{K}_{2} \mathrm{HPO}_{4}$, associated with microbial growth for 11 days.

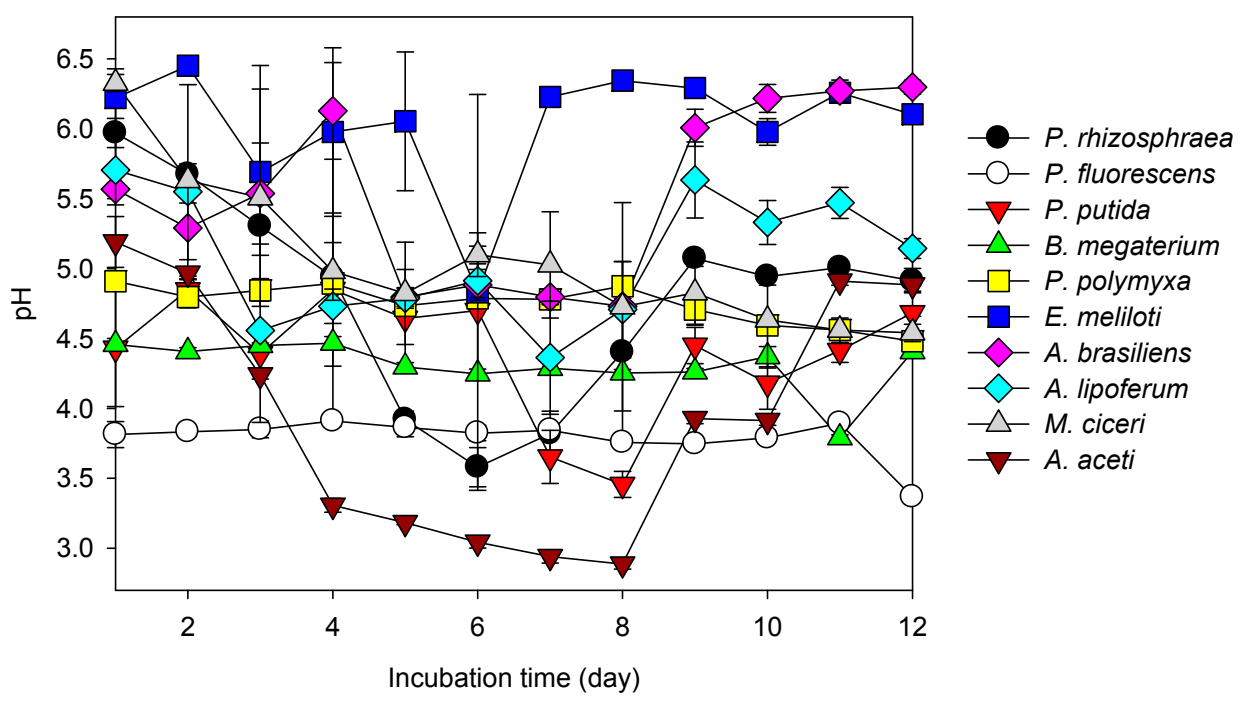

Figure 3. The $\mathrm{pH}$ changes induced by phosphate solubilizing bacteria (PSB) during incubation in Reyes minimal medium supplemented with $\mathrm{K}_{2} \mathrm{HPO}_{4}$.

\subsection{REE Leaching by the Test PSB from the Monazite-Bearing Ore and Comparison with the}

\section{Screening Study Data}

Ten PSB were introduced to leach REE from monazite-bearing ore (Figure 4). We detected $\sim 5.7 \mathrm{mg} / \mathrm{L}$ of cerium $(0.13 \%$ of leaching efficiency) and $2.8 \mathrm{mg} / \mathrm{L}$ of lanthanum $(0.11 \%)$ in the leaching liquor of $A$. aceti, and approximately $0.5-1 \mathrm{mg} / \mathrm{L}$ of cerium and lanthanum $(0.005 \%-0.01 \%)$ in the leaching liquors of $A$. brasilense, A. lipoferum, $P$. rhizosphaerae, and $M$. ciceri. Since acetic and malic acid were produced by $A$. aceti, A. brasilense, A. lipoferum, $P$. rhizosphaerae, and $M$. ciceri as stated above, REE such as cerium and lanthanum may form complexes with these acids. When REE cations $\left(\mathrm{Re}_{2} \mathrm{O}_{3}\right)$ are present in a system and acetic or malic acid is fully dissociated in aqueous solution, a complexation reaction may take place $\left(\right.$ at $\left.25^{\circ} \mathrm{C}\right)[26]$; 
$\mathrm{C}_{2} \mathrm{H}_{4} \mathrm{O}_{2} \leftrightarrow \mathrm{C}_{2} \mathrm{H}_{3} \mathrm{O}_{2}{ }^{-}+\mathrm{H}^{+}\left(p K_{a}=4.756\right)$

$3 \mathrm{C}_{2} \mathrm{H}_{3} \mathrm{O}_{2}{ }^{-}+\mathrm{Re}_{2} \mathrm{O}_{3} \leftrightarrow \mathrm{Re}\left(\mathrm{C}_{2} \mathrm{H}_{3} \mathrm{O}_{2}\right)_{3}$ (REE acetate complex)

Also, since malic acid is a diprotic acid, the possible complexes of REE reaction with malate anions are as follows;

$\mathrm{C}_{4} \mathrm{H}_{6} \mathrm{O}_{5} \leftrightarrow \mathrm{C}_{4} \mathrm{H}_{5} \mathrm{O}_{5}{ }^{-}+\mathrm{H}^{+}\left(p K_{a}=3.40\right)$

$3 \mathrm{C}_{4} \mathrm{H}_{5} \mathrm{O}_{5}{ }^{-}+\mathrm{Re}_{2} \mathrm{O}_{3} \leftrightarrow \mathrm{Re}\left(\mathrm{C}_{4} \mathrm{H}_{5} \mathrm{O}_{5}\right)_{3}$ (Rare earths malate complex)

$\mathrm{C}_{4} \mathrm{H}_{5} \mathrm{O}_{5}{ }^{-} \leftrightarrow \mathrm{C}_{4} \mathrm{H}_{4} \mathrm{O}_{5}{ }^{2-}+2 \mathrm{H}^{+}\left(p K_{a}=5.11\right)$

$3 \mathrm{C}_{4} \mathrm{H}_{4} \mathrm{O}_{5}{ }^{2-}+2 \mathrm{Re}_{2} \mathrm{O}_{3} \leftrightarrow \mathrm{Re}_{2}\left(\mathrm{C}_{4} \mathrm{H}_{4} \mathrm{O}_{5}\right)_{3}$ (Rare earths malate complex)

The role of low molecular weight organic acids such as acetic, malic, oxalic, and citric acids in metal dissolution has been discussed in many studies [7-9,27,28]. The ligands of the organic acids play a dominant role in dissolving metals, and the differences in the effect of metal dissolution is related to their chemical structure. For instance, citric acid has great chelating ability with metals because citrate (i.e., three carboxylic groups) can form stable chelates with 6-membered ring structures. While malic acid (dicarboxylic acid) is more stable than acetic acid (monocarboxylic acid) [29], REE leaching was observed in the $A$. aceti culture (where most of the leaching agent was acetic acid) because acetic acid production was higher than other organic acids production.

Mineralogical changes of the monazite-bearing ore before and after PSB leaching were also considered. As a variety of minerals that entrap monazite may be present, and these minerals may prevent contact of the organic acids produced by PSB as shown in the XRD patterns and the SEM images (Figures 5 and 6; Table 3). The X-ray pattern of the monazite-bearing ore shows the presence of dolomite $\left(\mathrm{CaMg}\left(\mathrm{CO}_{3}\right)_{2}\right)$, quartz $\left(\mathrm{SiO}_{2}\right)$, siderite $\left(\mathrm{FeCO}_{3}\right)$, pyrite $\left(\mathrm{FeS}_{2}\right)$, and monazite $((\mathrm{Ce}, \mathrm{La}, \mathrm{Pr}$, $\mathrm{Nd}, \mathrm{Th}, \mathrm{Y}) \mathrm{PO}_{4}$ ). The cerium and lanthanum-rich region (spot 1 and 2) had a spotty distribution surrounded by other minerals including $\mathrm{Mg}, \mathrm{Al}, \mathrm{Si}$, or Fe (spot 3 and 4). High carbon ratio in the spots was because of epoxy impregnation in preparing flat-polished specimens. XRD patterns of the monazite-bearing ore before and after leaching in this study showed a reduction in all peak intensities (Figure 6). High peaks of carbonate minerals (dolomite $\left(\mathrm{CaMg}\left(\mathrm{CO}_{3}\right)_{2}\right)$ and siderite $\left(\mathrm{FeCO}_{3}\right)$ ) were found and these minerals might consume the organic acids produced by PSB and prevent REE dissolution.

Differently from the phosphate solubilization test in liquid media (Figure 1), P. fluorescens, $P$. putida, B. megaterium, and $P$. polymyxa did not leach REE from the monazite-bearing ore. In the case of $A$. brasilense and A. lipoferum, even though they leached REE from the ore in spite of small leaching efficiency (Figure 4) and produced similar amounts of malic acid with $M$. ciceri and P. rhizosphaerae (Figure 2), they did not form halo zones (Table 2). This discrepancy sometimes happens because of the difference between cultivation in liquid media and on agar media. A liquid medium is preferred for the production of such organic acids because excreted products are readily available from a liquid culture and the cells are uniformly exposed to conditions of the medium [30]. However, the strongest leaching of REE was observed in the presence of $A$. aceti, as expected by both the results of the halo zone formation and the phosphate solubilization test. In the case of low-capacity bacteria, some errors may occur as stated above in determination of halo zone formation, but this method is still useful to roughly estimate phosphate solubilizing and organic acid producing abilities, as well as REE leaching capacities. Thus we believe that determination of halo zone formation can be used as a simple and rapid screening method to select high-capacity bacteria in REE leaching. 

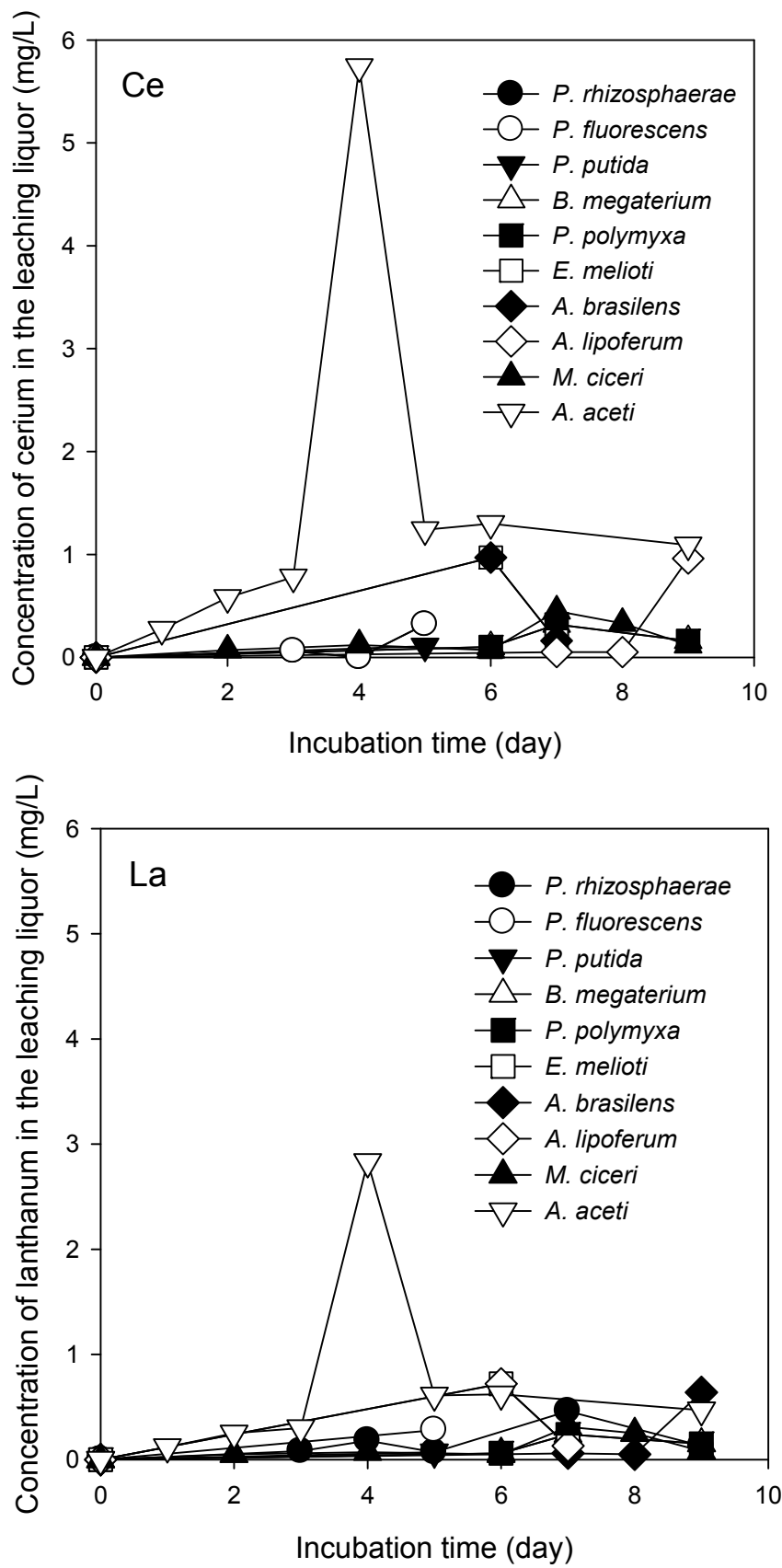

Figure 4. The concentrations of leached cerium and lanthanum from monazite-bearing ore by phosphate solubilizing bacteria (PSB) in Reyes basal liquid medium.

Table 3. Elemental compositions of the spots in Figure 5 by scanning electron microscopy/energy dispersive X-ray spectroscopy (SEM-EDS).

\begin{tabular}{ccccccccccccc}
\hline \multirow{2}{*}{ Spot No. in Figure 5 5 } & \multicolumn{10}{c}{ Mass \% } \\
\cline { 2 - 14 } & $\mathbf{C}$ & $\mathbf{O}$ & $\mathbf{M g}$ & $\mathbf{A l}$ & $\mathbf{S i}$ & $\mathbf{P}$ & $\mathbf{S}$ & $\mathbf{C a}$ & $\mathbf{F e}$ & $\mathbf{L a}$ & $\mathbf{C e}$ & Pr \\
\hline 1 & 82.1 & 4.88 & 1.67 & - & - & - & - & 7.06 & - & 0.18 & 4.1 & - \\
2 & 46.0 & 22.7 & 1.28 & - & 5.4 & - & 8.2 & - & - & 3.36 & 12.5 & 0.62 \\
3 & 61.3 & 16.4 & 1.05 & 0.24 & 8.77 & 2.15 & - & - & 9.26 & - & - & - \\
4 & 70.6 & 15.8 & - & 4.33 & 9.3 & - & 0.56 & - & - & - & - & - \\
\hline
\end{tabular}




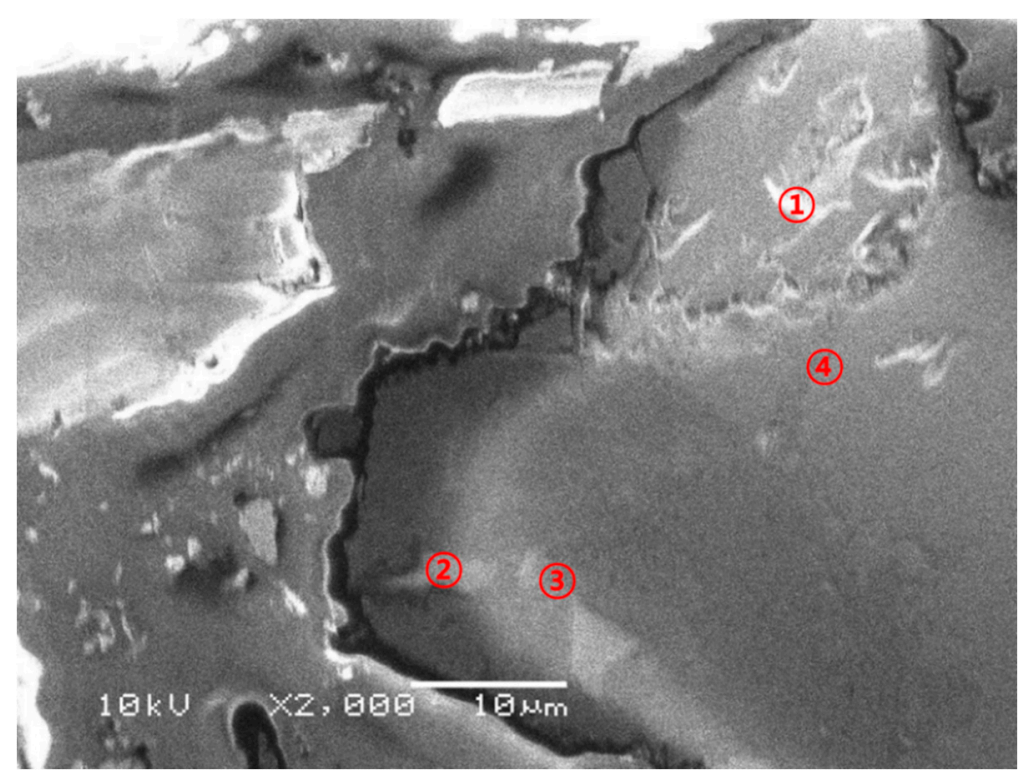

Figure 5. Scanning electron microscopic image of the raw monazite-bearing ore (3000× magnification). The detailed investigations are given in the text and Table 3 .
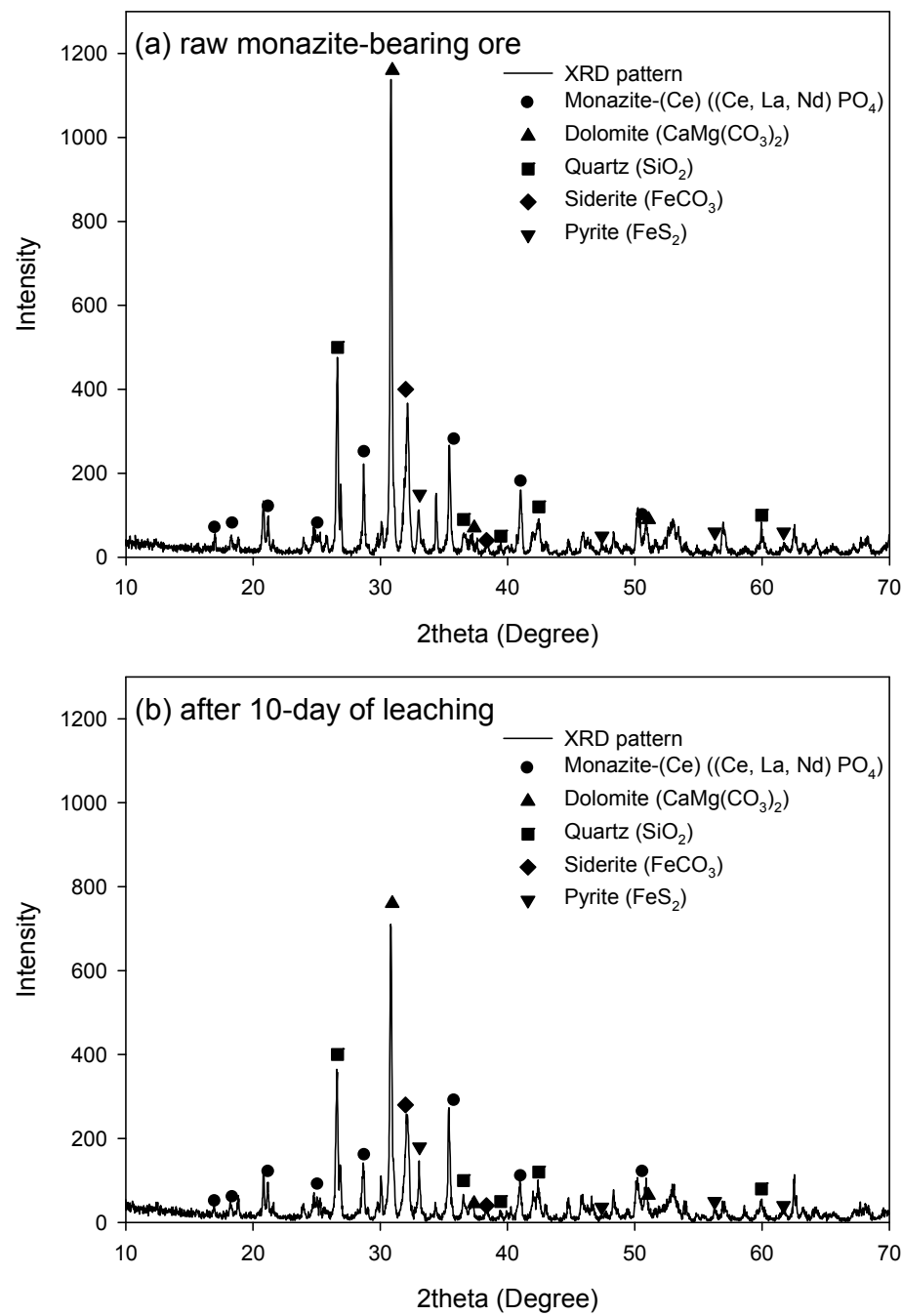

Figure 6. X-Ray diffraction (XRD) patterns of the monazite-bearing ore before and after leaching (10 days). 
Biological leaching technology has some advantages over other methods, as it is relatively simple, inexpensive, and environmental friendly. However, even though A. aceti showed the highest leaching efficiency of the PSB tested, the efficiency of extraction was only $\sim 0.13 \%$ (at least in batch-type experiments), which is still very low. The PSB used in this study have been used in soil improvement applications because they adapt well to soil environments; however, their organic acid producing and phosphate solubilizing ability is not that high. Thus, further studies are underway to explore the use of other microorganisms with good organic acid producing abilities for REE extraction applications, as well as to design continuous leaching systems so as to enhance leaching efficiency because the ore particles might not be exposed or contacted by the organic acid produced by the test PSB strains in a batch culture system.

\section{Conclusions}

The present study was conducted to use PSB to leach REE from monazite-bearing ore and to predict the REE leaching ability of PSB by determining halo zone formation on agar media and phosphate solubilization in liquid media. Among the ten test PSB strains, the phosphate solubilizing ability of $A$. aceti was the highest, based on results of halo zone formation and the phosphate solubilization test. Based on REE leaching data from the raw monazite-bearing ore by the test PSB, halo zone formation was found to be a useful method to select high-capacity bacteria in REE leaching.

\section{Acknowledgments}

This research was supported by the Basic Research Project (GP2015-005 and JP2013-005) of the Korea Institute of Geoscience and Mineral Resources (KIGAM), funded by the Ministry of Science, Information and Communications Technologies, and Future Planning of Korea.

\section{Author Contributions}

All of the authors were involved in the laboratory work, sample characterization, writing and revising of all parts of the manuscript.

\section{Conflicts of Interest}

The authors declare no conflict of interest.

\section{References}

1. British Geological Survey. Rare Earth Elements. Available online: http://www.MineralsUK.com (accessed on 27 March 2015).

2. Gupta, C.K.; Krishnamurthy, N. Extractive Metallurgy of Rare Earths; CRC Press: New York, NY, USA, 2005.

3. Maestro, P.; Huguenin, D. Industrial applications of rare earths: Which way for the end of the century. J. Alloy. Compd. 1995, 225, 520-528.

4. Habashi, F. Handbook of Extractive Metallurgy; Wiley-VCH: Heidelberg, Germany, 1997. 
5. Zongsen, Y.; Minbo, C. Rare Earth Elements and Their Applications; Metallurgical Industry Press: Beijing, China, 1995.

6. Park, H.-K.; Lee, J.-Y.; Cho, S.-W.; Kim, J.-S. Overview on the Technologies for Extraction of Rare Earth Metals. J. Korean Inst. Resour. Recycl. 2012, 21, 74-83.

7. Desouky, O.A.; El-Mougith, A.A.; Hassanien, W.A.; Awadalla, G.S.; Hussien, S.S. Extraction of some strategic elements from thorium-uranium concentrate using bioproducts of Aspergillus ficuum and Pseudomonas aeruginosa. Arabian J. Chem. 2011, doi:10.1016/j.arabjc.2011.08.010.

8. Hassanien, W.A.G.; Desouky, O.A.N.; HussienN, S.S.E. Bioleaching of some Rare Earth Elements from Egyptian Monazite using Aspergillus ficuum and Pseudomonas aeruginosa. Walailak J. Sci. Technol. 2014, 11, 809-823.

9. Goyne, K.W.; Brantley, S.L.; Chorover, J. Rare earth element release from phosphate minerals in the presence of organic acids. Chem. Geol. 2010, 278, 1-14.

10. Chung, H.; Park, M.; Madhaiyan, M.; Seshadri, S.; Song, J.; Cho, H.; Sa, T. Isolation and characterization of phosphate solubilizing bacteria from the rhizosphere of crop plants of Korea. Soil. Biol. Biochem. 2005, 37, 1970-1974.

11. Gadagi, R.S.; Sa, T. New isolation method for microorganisms solulbilizing iron and aluminum phosphates using dyes. Soil Sci. Plant Nutr. 2002, 48, 615-618.

12. Gadd, G.M. Fungal Production of Citric and Oxalic Acid: Importance in Metal Speciation, Physiology and Biogeochemical Processes. In Advances in Microbial Physiology; Poole, R.K., Ed.; Academic Press: Waltham, MA, USA, 1999; Volume 41, pp. 47-92.

13. Chen, Y.P.; Rekha, P.D.; Arun, A.B.; Shen, F.T.; Lai, W.A.; Young, C.C. Phosphate solubilizing bacteria from subtropical soil and their tricalcium phosphate solubilizing abilities. Appl. Soil Ecol. 2006, 34, 33-41.

14. Rodriguez, H.; Fraga, R. Phosphate solubilizing bacteria and their role in plant growth promotion. Biotechnol. Adv. 1999, 17, 319-339.

15. Jeong, S.; Moon, H.S.; Nam, K.; Kim, J.Y.; Kim, T.S. Application of phosphate-solubilizing bacteria for enhancing bioavailability and phytoextraction of cadmium (Cd) from polluted soil. Chemosphere 2012, 88, 204-210.

16. Peix, A.; Rivas, R.; Mateos, P.F.; Martínez-Molina, E.; Rodríguez-Barrueco, C.; Velázquez, E. Pseudomonas rhizosphaerae sp. nov., a novel species that actively solubilizes phosphate in vitro. Int. J. Syst. Evol. Microbiol. 2003, 53, 2067-2072.

17. Gholami, A.; Shahsavani, S.; Nezarat, S. The Effect of Plant Growth Promoting Rhizobacteria (PGPR) on Germination, Seedling Growth and Yield of Maize. Int. J. Biol. Life Sci. 2009, 1, $35-40$.

18. Tilak, K.V.B.R.; Ranganayaki, N.; Pal, K.K.; De, R.; Saxena, A.K.; Nautiyal, C.S.; Mittal, S.; Tripathi, A.K.; Johri, B.N. Diversity of plant growth and soil health supporting bacteria. Curr. Sci. 2005, 89, 136-150.

19. Halder, A.K.; Chakrabartty, P.K. Solubilization of inorganic phosphate by Rhizobium. Folia Microbiol. 1993, 38, 325-330.

20. Reyes, I.; Bernier, L.; Simard, R.R.; Tanguay, P.; Antoun, H. Characteristics of phosphate solubilization by an isolate of a tropical Penicillium rugulosum and two UV-induced mutants. FEMS Microbiol. Ecol. 1999, 28, 291-295. 
21. Briggs, P.H.; Meier, A.L. The Determination of Forty Two Elements in Geological Materials by Inductively Coupled Plasma-Mass Spectrometry; US Department of the Interior, US Geological Survey: Denver, CO, USA, 1999.

22. Katznelson, H.; Peterson, E.A.; Rouatt, J.W. Phosphate-dissolving microorganisms on seed and in the root zone of plants. Can. J. Bot. 1962, 40, 1181-1186.

23. Stumm, W.; Morgan, J.J. Aquatic Chemistry: Chemical Equilibria and Rates in Natural Waters; John Wiley \& Sons: Hoboken, NJ, USA, 2012.

24. Hwangbo, H.; Park, R.D.; Kim, Y.W.; Rim, Y.S.; Park, K.H.; Kim, T.H.; Suh, J.S.; Kim, K.Y. 2-Ketogluconic acid production and phosphate solubilization by Enterobacter intermedium. Curr. Microbiol. 2003, 47, 87-92.

25. Švitel, J.; Šturdik, E. 2-Ketogluconic acid production by Acetobacter pasteurianus. Appl. Biochem. Biotechnol. 1995, 53, 53-63.

26. Dawson, R.M.C. Data for Biochemical Research; Clarendon Press: Oxford, UK, 1959.

27. Qin, F.; Shan, X.-Q.; Wei, B. Effects of low-molecular-weight organic acids and residence time on desorption of $\mathrm{Cu}, \mathrm{Cd}$, and $\mathrm{Pb}$ from soils. Chemosphere 2004, 57, 253-263.

28. Debela, F.; Arocena, J.M.; Thring, R.W.; Whitcombe, T. Organic acid-induced release of lead from pyromorphite and its relevance to reclamation of $\mathrm{Pb}$-contaminated soils. Chemosphere 2010, $80,450-456$.

29. Bolan, N.S.; Naidu, R.; Mahimairaja, S.; Baskaran, S. Influence of low-molecular-weight organic acids on the solubilization of phosphates. Biol. Fertil. Soils 1994, 18, 311-319.

30. Pine, L.; George, J.R.; Reeves, M.W.; Harrell, W.K. Development of a chemically defined liquid medium for growth of Legionella pneumophila. J. Clin. Microbiol. 1979, 9, 615-626.

(C) 2015 by the authors; licensee MDPI, Basel, Switzerland. This article is an open access article distributed under the terms and conditions of the Creative Commons Attribution license (http://creativecommons.org/licenses/by/4.0/). 